\title{
Coping, Depression, Anxiety, Self-Efficacy and Social Support: Impact on Adjustment to Chronic Pain
}

\author{
Maria Alexandra Ferreira Valente ${ }^{1}$, José Luís Pais Ribeiro ${ }^{2}$, Mark P. Jensen ${ }^{3}$ \\ ${ }^{1}$ Faculdade de Psicologia e Ciências da Educação da Universidade do Porto, Portugal \& Fundação para \\ a Ciência e a Tecnologia (SFRH/BD/40956/2007), Portugal; ${ }^{2}$ Faculdade de Psicologia e Ciências da Educação \\ da Universidade do Porto, Portugal; ${ }^{3}$ University of Washington School of Medicine, Seattle, USA
}

Disponible online 30 de agosto de 2009

\begin{abstract}
Pain is a multidimensional, unique, and private experience. Contemporary biopsychosocial models of chronic pain hypothesize a key role for psychosocial factors as contributing to the experience of and adjustment to chronic pain. The psychosocial factors that have been most often examined as they relate to chronic pain include coping responses, attributions (such as self-efficacy), mood (including depression and anxiety), and social support. Knowledge concerning the relative importance of each of these factors to adjustment is necessary for understanding and developing effective psychosocial interventions. This article reviews the literature concerning the associations between psychosocial factors and adjustment to chronic pain, with a focus on coping, attributions, mood, and social support. Overall, the findings of this research are consistent with biopsychosocial models of chronic pain, and support continued research to help identify the causal relationships among key psychosocial variables and adjustment.
\end{abstract}

Keywords:

Chronic Pain, Coping, Mood, Attributions, Social Support

El dolor es una experiencia multidimensional, única, y privada. Los modelos biopsicosociales contemporáneos de dolor crónico hipotetizan que los factores psicosociales ejercen un papel clave tanto en la configuración de la experiencia de dolor crónico como en el proceso de ajuste de quien lo sufre. Los factores psicosociales más estudiados incluyen: el afrontamiento, las atribuciones (como la autoeficacia), el estado afectivo (tanto la depresión como la ansiedad) y el apoyo social. Conocer la importancia relativa de cada uno de éstos en los procesos de ajuste a la experiencia del dolor crónico es necesario para entender y desarrollar intervenciones psicosociales eficaces. Este artículo revisa la literatura sobre la relación entre factores psicosociales y procesos de ajuste al dolor crónico, especialmente afrontamiento, atribuciones, estado de ánimo, y apoyo social. En general, las conclusiones de este trabajo son compatibles con los modelos biopsicosociales de dolor crónico, y sugieren continuar las investigaciones para identificar las relaciones causales entre ciertas variables psicosociales y el ajuste al dolor crónico.

Palabras Clave:

Dolor Crónico, Afrontamiento, Estado de Ánimo, Atribuciones, Apoyo Social 


\section{Chronic Pain: A Subjective Experience}

Pain is a multidimensional and private experience that has been defined as chronic 3 months after initial onset (Merskey \& Bogduk, 1994; Miró, Nieto \& Huguet, 2008; Soares, 1999). Chronic pain is a source of suffering that can come to dominate the life of the patient and his/her family, and friends, as it can result in a complex set of somatic and psychosocial changes that undermine quality of life (Breivik, Collet, Ventafridda, Cohen \& Gallacher, 2006; Morlion et al., 2008). Although large regional and national differences have been reported in prevalence, severity and primary causes of pain (e.g. from $12 \%$ of prevalence in Spain to $30 \%$ in Norway), it has been estimated that chronic pain affects about one in each five adults of the European population (Breivik et al., 2006). The financial burden generated by chronic pain is at about the same level as that caused by cancer and cardiovascular diseases, and recognized as a major healthcare problem (Breivik et al., 2006; IASP, EFIC, 2005; Pain Associates' International Network, 2004; Morlion et al., 2008).

Without denying the biomedical factors that contribute to pain, in recent decades, there has been a steady increase in research studying the subjective nature of pain and an acknowledgement that the experience of pain is influenced by emotional, psychological, social and spiritual factors (e.g. López-Martínez, Esteve \& Ramírez-Maestre, 2008; Miró et al., 2008; Wachholtz, Pearce \& Koenig, 2007; Waddell, Newton, Henderson, Somervilee \& Main, 1993), consistent with the Gate-Control Theory (Melzack, 1979; Melzack \& Wall, 1965, 1982) and other contemporary models such as the Fear-Avoidance Model, Behavioral Model, the Functional Model and the Biopsychosocial Model. Despite criticisms that can be made about some details of each of these theories or models, there is substantial evidence supporting the basic tenets of models that incorporate psychosocial factors (Novy, Nelson, Francis \& Turk, 2005). For example, the associations between pain intensity or severity and disability tend to be very weak, while the associations between psychosocial factors and disability are much stronger (McCraken, Zayfert \& Gross, 1992; Waddell et al., 1993).

\section{Psychosocial Factors and Adjustment to Chronic Pain:Patterns, Inconsistencies and Gaps}

There have been many psychosocial factors that have been studied with respect to chronic pain. They include pain-related fear, pain coping responses, mood (e.g. anxiety, depression, happiness, boredom), attributions (e.g. individual beliefs, meaning assigned to pain, self-efficacy and catastrophizing), and the social context (e.g. social support), among others (e.g. Baker, Buchanan \& Corson, 2008; Cipher \& Fernandez, 1997; Evers, Kraiaimaat, Geenen, Jacobs \& Biglsma, 2003; Keefe, Rumble, Scipio, Giordano \& Perry, 2004; Meredith, Strong
\& Feeney, 2006; Miró et al., 2008; Nicholas, 2007; Robb, Williams, Duvivier \& Newham, 2006; Tunks, Weir \& Crook, 2008; Turk \& Okifuji, 2002; Vlaeyen, Kole-Snijders, Boeren \& vanEek, 1995; Waddell et al., 1993). However, the most commonly studied psychosocial factors as they relate to pain and adjustment to chronic pain include: (1) pain coping responses, (2) depression, (3) anxiety, (4) attributions, and (5) social support.

\section{Pain Coping Responses}

There is a vast literature on the association between coping responses and chronic pain, especially in populations with chronic non-cancer pain. "Pain" is often not a single stressor to be coped with as much as a cluster of multiple stressors that are unique to each patient, involving: (1) the distress associated with the experience of pain; (2) concerns about the causes of pain; and (3) the effects of pain (e.g., unemployment, depression, sleep disturbance, etc.). As a result, pain coping responses are also complex and unique to each patient (Dysvik, Natvig, Eikeland \& Lindstrom, 2005) and different people with chronic pain use a large variety of different coping strategies to deal with pain and its effects on their lives (e.g. Esteve, Ramírez-Maestre \& López-Martínez, 2007; López-Martínez et al., 2008).

Different researchers and clinicians often emphasize different types or categories of coping strategies, such as: (1) problem-focused coping strategies versus emotion-focused coping strategies (Folkman \& Lazarus, 1980; Lazarus \& Folkman, 1984); (2) confrontation versus avoidance coping strategies (Lethem, Slade, Troup \& Beutley, 1983); and (3) active coping strategies (individual efforts to manage or deal with pain through their own resources and to continue to function despite the pain) versus passive coping strategies (e.g. restriction of activities, rest, catastrophizing, expression of emotions, depending on others) (Jensen, Turner, Romano \& Karoly, 1991; Ramírez-Maestre, Esteve \& López, 2008).

Research results are not always consistent with respect to the relationship of global categories of coping strategies with pain experience, particularly with regard to problem-focused vs. emotion-focused coping. For this reason, studies that have used Lazarus and Folkman's coping model as a theoretical basis have not proved that useful. As stated by Van Damme and colleagues (Van Damme, Crombrez \& Eccleston, 2008), in the context of chronic pain, it may be more useful to consider coping as reflecting motivation for different goals (e.g., pain relief vs. improved function) and with respect to how they contribute (or not) to meaningful life goals.

In this context, some authors have proposed acceptance as another type of coping response (willingness to experience pain without trying to control it and persist in healthy activities despite the pain and without its influence) (McCracken, Vowles \& Gauntlett-Gilbert, 2007; Páez-Blarrina et al., 2008; Van Damme et al., 2008). This construct appears to overlap, at 
least in part, with the concepts of active and wellness-focused coping (Esteve et al., 2007; Jensen, Turner, Romano \& Nielson, 2008). According to the motivational approach of coping (Páez-Blarrina et al., 2008; Van Damme et al., 2008), acceptance can also be conceptualized as an accommodative way of coping, as opposed to attempts to diminish the impact of pain (assimilative coping). In fact, according to Van Damme and colleagues (2008), when a meaningful goal is blocked by pain, one can either attempt to diminish the impact of pain in order to achieve goals, or reappraise the goal (e.g., reflected by acceptance, devaluing the importance of blocked goals and/or engaging in other goals less affected by pain).

Similarly, some investigators are beginning to consider the role of religious or spiritual coping strategies, such as praying, hoping, religious attributions and spiritual support (Dunn \& Horgas, 2004; Wachholtz et al., 2007), expanding the biopsychosocial model into a biopsychosociospiritual model of pain. The hypothesis is that spiritual beliefs and practices can influence cognitive and emotional processes, which in turn may impact biological mechanisms and influence the experience of pain.

The decision to use a specific coping response or set of coping responses is influenced by a large number of variables. Among them are culture, personality, age and development stage, cognitive appraisals (e.g., whether or not the stressor is appraised as threat/harm versus as challenge), individual beliefs (about cause of pain, fear-avoidance beliefs, beliefs about the importance of engaging versus not engaging in pain self-management behaviors and beliefs about self ability to engage those behaviors), attributions and motivation, perceived control, individual habits and skills (see Jensen, Nielson \& Kerns, 2003; Lazarus \& Folkman, 1984; McCraken et al., 1992; Naughton, 1997; Ramírez-Maestre, López-Martínez e Esteve, 2004; Ramírez-Maestre et al., 2008; Van Damme et al., 2008; Vlaeyen et al., 1995; Waddell et al., 1993).

The sex of the patient is yet another factor that could influence coping responses. For example, there may be sex differences in the way individuals appraise pain (some stu $\neg$ dies indicate that women tend more than men to appraise pain as a threat, with gender role possibly acting as a mediator) (Ramírez-Maestre et al., 2008; Sanford, Kersh, Thorn, Rich \& Ward, 2002; Unruh, 1996), and in some beliefs about pain (for example, women tend to report greater levels of catastrophizing related to pain than men, although the literature is not entirely consistent on this issue) (see Edwards, Haythornthwaite, Sullivan \& Fillingim, 2004), and these differences could potentially influence the use of coping responses. A third potential sex difference is the possibility that, due to social role functioning, men may engage in more active coping strategies than women (Ramírez-Maestre et al., 2004). Preliminary results support this possibility, as they indicate that females are more likely than males to engage in social support seeking, catastrophizing and rumination (Jensen, Turner, Romano \& Lawler, 1994; Tamres,
Janicki \& Helgeson, 2002; but see Ramírez-Maestre et al., 2004 for negative findings with respect to sex differences in active vs passive coping).

For both research and clinical purposes, it may be useful to distinguish adaptive (strategies that tend to be associated with a decrease in frequency or intensity of pain, or in the negative effects of pain on patients' lives) from maladaptive pain coping strategies (responses that tend to be associated with increases in pain or pain-related disability), as this classification can be based on empirical findings and has clear clinical relevance (Soares, 1999). Research shows an interesting pattern with respect to the association between coping responses that have been classified in this way and patient outcomes. Specifically, although some adaptive coping strategies (e.g., relaxation and exercise) may be useful for some individuals, the research indicates a stronger (negative) association between coping strategies considered maladaptive and measures of patient functioning than the (positive) association between coping strategies considered adaptive and measures of patient functioning (e.g. López-Martínez et al., 2008). This pattern of findings raises the interesting possibility that it may be more important for patients to cease using maladaptive coping responses than to start using adaptive ones.

However, a coping response is not likely to be "adaptive" or "maladaptive" for every patient or even within the same patient at different times, as the adaptability of coping seems to depend on a large broad of factors (for example circumstances, motivation, goals) (Van Damme et al., 2008). As a result, the effects of a coping response may be best evaluated in light of its effects for any patient in each situation (Ramírez-Maestre et al., 2008; Ribeiro \& Santos, 2001). Thus, there are likely situations when a specific coping response that is usually maladaptive might be adaptive (e.g., resting appropriately after engaging in an important activity; seeking social support when the available social resources are well appraised), or a coping response that is usually adaptive might be maladaptive (e.g., exercise can be maladaptive if it leads to repetitive stress injuries; excessive task persistence can be maladaptive when the aims are unreachable due to pain) (Van Damme et al., 2008; Vlaeyen et al., 1995)

For the most part, however, passive and emotion-focused coping responses, as well as avoidance, tend to be maladaptive, even if they sometimes result in short-term reductions in pain and suffering. In the long term, these coping responses tend to be associated with an increase in pain intensity, greater disability, poor psychosocial adjustment and higher levels of anxiety and depression across numerous different chronic pain populations (e.g. Keefe et al., 2004; Kraaimaat \& Evers, 2003; Lethem et al., 1983; López-Martínez et al., 2008; Reuter et al., 2006; Tunks et al., 2008; Turner, Ersek \& Kemp, 2005; Vlaeyen et al., 1995). As with many maladaptive coping responses, however, passive coping might be appropriate at times; especially when the situation cannot be changed. In this case, avoidance might be beneficial, at least in the short term, for reducing pain inten- 
sity (Dysvik et al., 2005), although it may result in greater pain intensity, depression and anxiety in the long-term.

Similarly, active and problem-focused strategies tend to be considered adaptive and beneficial, especially in situations that can be controlled and changed. But even here the findings are not entirely consistent (Jensen et al., 1991; Kraaimaat \& Evers, 2003; Ramírez-Maestre et al., 2008). Some studies indicate that the use of such coping strategies is associated with decreases in pain intensity, disability, depression, and distress, as well as increases in physical and psychological functioning, across different samples of individuals with chronic pain (e.g. Dysvik et al., 2005; Jensen et al., 1991; López-Martínez et al., 2008; Newth \& Delongis, 2004; Turner et al., 2005). In other studies, however, the associations between these coping responses and measures of pain were weak and nonsignificant (Dysvik et al., 2005; Evers et al., 2003). Also, it is important to keep in mind that, in general, the findings show stronger associations between coping and measures of pain adjustment than between coping and pain experience itself (e.g. Dysvik et al., 2005; Esteve et al., 2007; López-Martínez et al., 2008); that is, coping may be more important for buffering the effects of pain on function, and less important for reducing or eliminating pain severity.

It is possible that active coping does not directly result in a decrease in pain intensity and disability, but the benefits of these coping responses may be mediated by their effects on the use of (maladaptive) passive coping responses, although their use is not mutually exclusive (Esteve et al., 2007; López-Martínez et al., 2008; Ramírez-Maestre et al., 2008). Similarly, the use of active coping strategies may, through their association with acceptance, result in better physical, psychological and emotional functioning (Esteve et al., 2007, McCracken et al., 2007).

Recent findings have suggested that "acceptance" may also be classified as an adaptive coping strategy in pursuit of pain adjustment, especially when the individual is dealing with pain interference with a valued goal (Van Damme et al., 2008). In a recent study by Páez-Blarrina and colleagues (2008), for example, the authors compared the effects of two therapeutic strategies (cognitive- and control-based protocol versus acceptance-based protocol). The results showed an increase in pain tolerance and decrease on pain intensity in both groups. However, only the patients given acceptance-based treatment reported an increased in task performance.

When we consider the role of spiritual or religious coping, the results are again inconsistent. Indeed, while some authors claim that there is a negative correlation between this construct and pain intensity, there is, in some studies, a paradoxical positive association between meditation, faith/praying and pain intensity (Francoa, Garcia \& Picabiab, 2004; Wachholtz et al., 2007).

Acknowledging that inconsistent findings are more common than consistent ones, there has emerged some consistency concerning some specific coping strategies. Specifically, most studies suggest that for most people, most of the time, avoidance, pain-contingent rest, and guarding are maladaptive and result in increased pain and disability over time (e.g. Arraras, Wright, Jusue, Tejedor \& Calvo, 2002; Valente, PaisRibeiro \& Jensen, 2009). As a result, unless there is a specific medical contraindication, patients should probably be advised to move without guarding and be (at least) moderately active regardless of pain, willing to notice it and yet pursuit valuable goals less affected by pain.

Another factor that can complicate our understanding of the associations between coping and chronic pain is the possibility that there are confounding variables which might explain the associations found. In other words, it is possible that coping does not directly impact pain/functioning, but that both coping and pain/functioning are affected by other variables (Esteve et al., 2007; Ramírez-Maestre et al., 2004; Vlaeyen et al., 1995). For example, an association between depression and the use of emotion-focused coping strategies has been established, both in samples of patients with cancer pain as well as in samples of patients with non-cancer pain (e.g., Dysvik et al., 2005; Reuter et al., 2006). At the same time, there is also a negative association between depression and the use of active coping strategies (Esteve et al., 2007). Depression, through its possible effects on both coping and functioning, is a possible confounding variable that could explain some, or even all, associations found between coping and pain-related adjustment.

Other psychosocial variables may act as mediators between coping and functioning. For example, active coping responses and/or relaxation could help patients less anxious and reduce their focus on pain and through this mechanism change their experience of pain. Examples of such coping responses could include task persistence in spite of the pain as well as some spiritual strategies (e.g. meditation, praying). Even faith, the pattern of prayer and spiritual support, could potentially impact the perception of social support. Ramírez-Maestre and colleagues (2004), on the other hand, proposed that if personality can predispose one to use different coping responses (neuroticism predispose to the use of passive coping responses), and modulate as well pain perception, coping has, on the other hand, a modulating effect on the relationship between certain personality variables and pain intensity.

\section{Depression}

The association between the presence and severity of chronic pain and symptoms of depression is well established (Baker et al., 2008; Keogh, MacCracken \& Eccleston, 2006; Munce \& Stewart, 2007; Miró et al., 2008; Woby, Roach, Urmston \& Watson, 2007), and depression spectrum disorders are common among people with chronic pain (Bär et al., 2005; Dysvik et al., 2005; Newth \& Delongis, 2004; Soares, 1999). Sex differences have been observed with respect to the association between depression and pain (e.g. Keogh et al., 2006; Munce \& Stewart, 2007), consistent with prevalence studies that note a higher pre- 
valence of both depression and chronic pain in women (Munce \& Stewart, 2007; Tsang et al., 2008), as well as the higher prevalence of depressive symptoms in women with chronic pain when compare to men with chronic pain. At the same time, some studies indicate that women have less emotional reaction and/or emotional association with their pain reports (Robinson et al., 2005). Clearly, further research is needed to clarify sex differences in affective response to and emotional association with pain.

Depression can be the result of biological factors associated with the cause of pain (e.g., cancer can produce both pain and symptoms of fatigue and depression). Depression can also be caused by the attributions a patient has about the pain problem, and ultimately influence the patient's ability to function despite pain (Jay, Elliot \& Varner, 1986; Robb et al., 2006). These is particularly true with respect to highly threatening diagnoses (e.g., cancer), because people can associate the experience of pain with the seriousness of the disease and the proximity of death, or even feel fear of a relapse, as well as feel anger when interpret their pain as a result of unnecessary treatment (Robb et al., 2006). Moreover, there is evidence that the use of tricyclic antidepressants and some mood stabilizers can be effective in alleviating health problems associated with pain (Miró et al., 2008).

Depression associated with pain can contribute to sadness, passivity, low self-esteem and decreases in the belief that pain can be managed or controlled (Soares, 1999). Depression can also contribute to the experience of pain itself, given evidence that people with depression or a depressive personality have a greater sensitivity to acute and chronic pain (Bär et al., 2005; Miró et al., 2008). Indeed, it appears that a significantly greater proportion of people with major depression, compared to people without depression, suffer from chronic pain (66\% vs. 43\%) (Arnow et al., 2006). Also, it is accepted that positive and negative feelings can increase or decrease the pain intensity and are frequently correlated to pain related disability (Dysvik, Vinsnes \& Eikland, 2004; Keogh et al., 2006; Newth \& Delong, 2004).

\section{Anxiety}

The research literature also shows consistent associations between measures of anxiety and pain, suggesting the possibilities that: (1) pain contributes to feelings of anxiety; (2) anxiety can make people more sensitive to pain and its negative effects; and also that (3) anxiety, either associated or not with fear, predicts pain related disability by contributing to hypervigilance and avoidance behaviors, maintaining the pain experience (e.g. Coniam \& Diamond, 2001; Keefe et al., 2004; McCraken et al., 1992; Strahl, Kleinknecht \& Dinnel, 2000; Tan, Jensen, Thornby, Rintala \& Anderson, 2008; Vlaeyen \& Linton, 2000; Woby et al., 2007). For example, the perception of pain may contribute to expectations that an event or behavior may cause or amplify pain, which can then increase anxiety and fear, and this in turn result in hypervigilance to bodily sensations and avoidance behaviors, followed by disability, disuse and depression, and ultimately to maintenance and exacerbations of pain (McCraken et al., 1992; Vlaeyen et al., 1995; Vlaeyen \& Linton, 2000).

Over time, and as pain becomes chronic, some individuals may transition to a permanent state of anxiety, resulting in chronic muscle tension and anticipatory anxiety, which can then lead to avoidance behavior and disability. As people stop performing usual activities (especially those, perhaps, that involve moving the body areas that are most painful), this can lead to less mobility, muscle atrophy, and an increase of muscular tension, all of which can then make patients more prone to experience pain flare-ups. Decreases in activities, especially those that provide meaning and reinforcement, can result in greater social isolation, decreased self-efficacy, increased feelings of uselessness, and subsequent increases in anxiety and depression (McGuire, Hogan \& Morrison, 2008), as proposed by the fear-avoidance model (Lethem et al., 1983; Vlaeyen et al., 1995).

On the other hand, the association between anxiety and pain could operate, at least in part, via a somatic mechanism. In this case, anxiety contributes to an increase of muscular tension, which then increases nociceptive input and the experience of pain (Miró et al., 2008; Soares, 1999; Woby et al., 2007). Although an association between anxiety and chronic pain is well-established, some authors have pointed the possibility of existent sex differences, as it is possible that anxiety is related to pain and adjustment in men but not among women (Edwards, Augustson \& Fillingim, 2000; Robinson et al., 2005).

\section{Attributions/Beliefs}

A large number of studies have examined the associations between attributions (beliefs, schema, etc.) and adjustment to pain. From this research, two attributions have emerged as particularly important: catastrophizing cognitions and self-efficacy beliefs. Catastrophizing may be defined as an exaggerated and overly negative evaluation of stressful events, and in the particular case of pain, as interpretation of pain as a threat, leading to focus more on the negative aspect of the situation, interpret physical arousal as pain cues, fear of pain and avoidance behaviors (Vlaeyen et al., 1995; Vlaeyen \& Linton, 2000). Whether viewed as a coping response (e.g. Keefe et al., 2004; Rosentiel \& Keefe, 1983; Sullivan, Bishop \& Pivik, 1995), or a cognition/ belief domain (e.g. Jensen, Turner \& Romano, 2001; Vlaeyen et al., 1995), there is uniform agreement that catastrophizing is a maladaptive response. Research shows that higher levels of catastrophizing are linked to higher levels of pain intensity, greater disability, poorer psychosocial adjustment, higher levels of anxiety and depression (e.g. Francoa et al., 2004; Esteve et al., 2007; Reuter et al., 2006; Severeijns, Vlaeyen, van den Hout \& Weber, 2001; Tunks et al., 2008; Turner, Jensen, Warms \& Cardenas, 2002; Vlaeyen \& Linton, 2000). 
Although the fear-avoidance model (Lethem et al., 1983; Vlaeyen et al., 1995) is commonly used to understand the role that catastrophizing plays in adjustment to pain, a neurophysiological model of catastrophizing has recently emerged (Woby et al., 2007). This model proposes that catastrophizing cognitions are associated with higher levels of brain activity in the areas of anticipation and attention to pain, emotional aspects of pain and motor control (Woby et al., 2007), and that these processes could underlie physical inactivity and increased pain experience, which can then contribute to physical deterioration and the development of chronicity (Mellegard et al., 2001).

Self-efficacy has been defined as the belief or experience that one can engage in a behavior that is necessary to produce a desired outcome (Bandura, 1977 cit. in Anderson et al., 1995). It represents a personal judgment about how well a person thinks he or she is able to carry out certain behaviors in a particular situation (Arnstein, 2000). Self-efficacy is based on and is continuously modified by the information provided by personal and vicarious experience (Mueller, Hartmann, Mueller \& Eich, 2003). Research findings indicate a consistent trend for low levels of self-efficacy to be associated with a higher disability in people with chronic pain (Arnstein, Caudill, Mandle, Norris \& Beasley, 1999; Meredith et al., 2006, Nicholas, 2007; Woby et al., 2007), lower levels of pain tolerance and higher levels of pain intensity in samples of people with chronic pain (Meredith et al., 2006; Waddell et al., 1993; Woby et al., 2007).

Self-efficacy beliefs are thought to be important determinants of other thoughts, feelings and coping responses (Bandura, 1986, Turner et al., 2005), which in turn affect functioning. In general, the person with chronic pain will use coping responses more effectively if he or she believes that he or she is capable of performing those responses (Bandura, 1977 cit. in Mueller et al., 2003). This hypothesis is consistent with the results reported by Brown and Nicassio (1987), in a sample of patients with chronic pain, who found that participants with higher selfefficacy tended to use active coping strategies, while those with lower self-efficacy were more likely to use passive coping strategies to deal with their pain. Similarly, Nicholas (2007) found a positive correlation between self-efficacy and the use of active coping strategies of the Coping Strategies Questionnaire, and a negative correlation with catastrophizing. Moreover, selfefficacy has been shown to be negatively associated with both anxiety and depression (Arnstein et al., 1999; Arnstein, 2000, Nicholas, 2007), suggesting that individuals who believe that they are able to handle and control pain and related symptoms are less likely to have depression and feel helpless or hopeless.

\section{Social Support}

A number of investigators have hypothesized both positive and negative moderating effects of social support and its effects on chronic pain (Kerns, Rosenberg \& Otis, 2002; López-Martínez et al., 2008; Tsai, Tak, Moore \& Palencia, 2003; Zaza,
Reynob \& Moulin, 2000). Santos and colleagues (Santos, Ribeiro \& Lopes, 2003) define social support as a coping resource that can reduce the adverse psychological effects of stressors, and hypothesize that satisfaction with social support would be positively associated with the use of adaptive coping strategies. Their findings supported this hypothesis, suggesting that social support and coping are interdependent. Moreover, general beliefs that others are available to provide emotional comfort and practical assistance in times of need appear to be beneficial to health and well-being (Navalhas, 1998, Santos et al., 2003). In fact, research in many different populations indicates a positive association between social support and physical and psychological functioning, as the quality and quantity of social support (positive emotional support) has a positive influence in mood, and the lack of social support is associated to higher levels of depression and poorer pain adjustment (e.g. Campbell, Clauw \& Keefe, 2003; López-Martínez et al., 2008; Romano, Turner \& Jensen, 1997; Tsai et al., 2003).

However, the findings regarding the associations between measures of social support and pain-related outcomes are inconsistent, perhaps due to the differences in how social support is defined across studies (López-Martínez et al., 2008). Although, the findings to date suggest the possibility that social support can reduce the negative effects of pain on physical and psychological functioning, separate from any effects of social support on coping, in some studies greater social support is, in fact, associated to higher levels of pain intensity (López-Martínez et al., 2008; Zaza \& Baine, 2002). Thus, it is possible that social support can sometimes act as a reinforcer of pain behavior, as solicitous response of the spouse contribute to increase pain and disability by reinforcing pain behaviour (López-Martínez et al., 2008).

\section{Future Research}

As a group, the findings reviewed above suggest important interdependence and possible influences not only between psychosocial factors and pain, but also among the psychosocial factors, underlying the need for studies that would examine and test for possible mediation and moderation effects. Moreover, there is a need for longitudinal and experimental studies that could clarify the causal nature of the relationships between psychosocial variables and important outcome domains (e.g. Arnstein, 2000; Wolff et al., 2008). The fear-avoidance model (Lethem et al., 1983; Vlaeyen et al., 1995) and the recent works begun by some investigators in this area provide (e.g. Arnstein, 2000; Wolff et al., 2008) excellent examples of how the field could move forward.

\section{Clinical implications}

Clinically, the findings support the continued use of psychosocial interventions to help patients better manage pain and its effects. Interventions that encourage adaptive attribu- 
tions (e.g., self-efficacy) and coping (e.g., maintaining activity despite pain and acceptance) and that discourage maladaptive attributions (e.g., catastrophizing) and coping (e.g., guarding) should be provided to patients who have not yet learned to manage pain adequately. Depression and anxiety should be consistently assessed, and, when found to be clinically elevated, treated appropriately.

Given the clear possibility that not all "adaptive" attributions and coping responses are, in fact, adaptive for all patients in all situations (and similarly, that not all "maladaptive" attributions and coping response are maladaptive for all patients), it is likely that treatments will need to be tailored to fit each patient. Multidisciplinary pain treatment programs should take into account the importance of addressing first those psychological factors that have proven to be most important in diverse samples of patients with chronic pain, such as the negative factors of guarding, pain-contingent rest, and catastrophizing, as a way to minimize their negative effects. Efforts should then be made to decrease the emotional impact of pain and promote adaptive behavioral changes, increasing the use of distraction techniques, relaxation, self-efficacy, acceptance and goals reappraisal to help the patient achieved valued life goals.

\section{Summary}

The findings of the studies reviewed in this paper demonstrate important associations between the experience and effects of chronic pain and key psychosocial variables, even if their interdependence is not always clear. The findings support the need for further research to clarify the nature of the associations among psychosocial variables and important functioning domains, as well as for adapting intervention strategies to address and alter the psychosocial factors that have proven to be most closely linked to adjustment to chronic pain, such as the addressing emotional impact of pain, increasing selfefficacy beliefs and acceptance, decreasing catastrophizing, guarding and pain-contingent rest, when present, and promote the reappraisal of goals.

\section{References}

Anderson, K., Dowds, B., Pelletz, R., Edwards, T., \& PeetersAsdourian, C. (1995). Development and initial validation of a scale to measure self-efficacy beliefs in patients with chronic pain. Pain, 63, 77 -84.

Arnstein, P. (2000). The mediation of disability by self efficacy in diferent samples of chronic pain patients. Disability and Rehabilitation, 22, 794- 801.

Arnstein, P., Caudill, M., Mandle, C., Norris, A., \& Beasley, R. (1999). Self efficacy as a mediator of the relationship between pain intensity, disability and depression in chronic pain patients. Pain, 80, 483-491.
Arnow, B., Hunkeler, E., Blasey, C., Lee, J., Constantino, M., Fireman, B., et al. (2006). Comorbid depression, chronic pain, and disability in primary care. Psychosomatic Medicine, 68, $262-268$.

Arraras, J., Wright, S., Jusue, G., Tejedor, M., \& Calvo, J. (2002). Coping style, locus of control, psychological distress and pain-related behaviours in cancer and other diseases. Psychology, Health \& Medicine, 7, 181-187.

Baker, T., Buchanan, N., \& Corson, N. (2008). Factors influencing chronic pain intensity in older black women: Examining depression, locus of control, and physical health. Journal of Women's Health, 17, 869-878.

Bandura, A. (1986). Social foundations of thought and action: a social cognitive theory. New Jersey: Englewood Cliffs.

Bär, K., Brehm, S., Boettger, M., Boettger, S., Wagner, G., \& Sauer, H. (2005). Pain perception in major depression depends on pain modality. Pain, 117, 97-103.

Breivik, H., Collet, B., Ventafridda, V., Cohen, R., \& Gallacher, D. (2006). Survey of chronic pain in Europe: Prevalence, impact on daily life, and treatment. European Journal of Pain, 10, 287-333.

Brown, G., \& Nicassio, P. (1987). The development of a questionnaire for the assessment of active and passive coping strategies in chronic pain patients. Pain, 31, 53-65.

Campbell, L., Clauw, D., Keefe, F. (2003). Persistent pain and depression: a biopsychosocial perspective. Biological Psychiatry, 54, 399-409.

Cipher, D., \& Fernandez, E. (1997). Expectancy variables predicting tolerance and avoidance of pain in chronic pain patients. Behaviour Research and Therapy, 35, 437-444.

Coniam, S., \& Diamond, A. (2001). Controlo da dor (2. ${ }^{a}$ Ed.). Lisboa: Climepsi Editores.

Dunn, K., \& Horgas, A. (2004). Religious and non religious coping in older adults experiencing chronic pain. Pain Management Nursing, 5, 19-28.

Dysvik, E., Natvig, G, Eikeland, O., \& Lindstrom, T. (2005). Coping with chronic pain. International Journal of Nursing Studies, 42, 297-305.

Dysvik, E., Vinsnes, A., \& Eikeland, O. (2004). The effectiveness of a multidisciplinary pain management programme managing chronic pain. International Journal of Nursing Practice, 10, 224-234.

Edwards, R., Augustson, E., \& Fillingim, R. (2000). Sex-specific effects of pain-related anxiety on adjustment to chronic pain. The Clinical Journal of Pain, 16, 275-276.

Edwards, R., Haythornthwaite, J., Sullivan, M., \& Fillingim, R. (2004). Catastrophizing as a mediator of sex differences in pain: differential effects for daily pain versus laboratory induced pain. Pain, 111, 335-341.

Esteve, R., Ramírez-Maestre, C., \& López-Martínez, A. (2007). Adjustment to chronic pain: the role of pain acceptance, coping strategies, and pain-related cognitions. Annals of Behavioral Medicine, 33, 179-188. 
Evers, A., Kraaimaat, F., Geenen, R., Jacobs, J., \& Biglsma, J. (2003). Pain coping and social support as predictors of long-term functional disability and pain in early rheumatoid arthritis. Behaviour Research and Therapy, 41, 1295-1310.

Folkman, S., \& Lazarus, R. (1980). An analysis of coping in a middle-aged community sample. Journal of Health and Social Behavior, 21, 219-239.

Francoa, L., Garcíaa, F., \& Picabiab, A., (2004). Assessment of chronic pain coping strategies. Actas Espanholas de Psiquiatria, 32, 82-91.

IASP, EFIC. (2005). Factsheet 4A: Unrelieved pain is a major global healthcare problem. Retrieved on May, 15, 2009 from http://www.iasp-pain.org/AM/Template. cfm?Section=Press_Release $\&$ Template $=/ \mathrm{CM} /$ ContentDisplay.cfm \&ContentID $=2908$

Jay, S., Elliot, C., \& Varni, J. (1986). Acute and chronic pain in adults and children with cancer. Journal of Consulting and Clinical Psychology, 54, 601-607.

Jensen, M., Nielson, W., \& Kerns, R. (2003). Toward the development of a motivational model of pain self-management. The Journal of Pain, 4, 477-492.

Jensen, M., Turner, J., \& Romano, J. (2001). Changes in beliefs, catastrophizing, and coping are associated with improvement in multidisciplinary pain treatment. Journal of Consulting and Clinical Psychology, 69, 655-662.

Jensen, M., Turner, J., Romano, J., Karoly, P. (1991). Coping with chronic pain: A critical review of the literature. Pain, 47, 249-283.

Jensen, M., Turner, J., Romano, J., \& Lawler, B. (1994). Relationship of pain-specific beliefs to chronic pain adjustment. Pain, 57, 201-309.

Jensen, M.P., Turner, J.A., Romano, J.M., \& Nielson, W.R. (2008). Chronic Pain Coping Inventory: Professional Manual. Lutz, FL: Psychological Assessment Resources.

Keefe, F., Rumble, M., Scipio, C., Giordano, L., \& Perri, L. (2004). Psychological aspects of persistent pain: current state of the science. The Journal of Pain, 5, 195-211.

Keogh, E., MacCracken, L., \& Eccleston, C. (2006). Gender moderates the association between depression and disability in chronic pain patients. European Journal of Pain, 10, 413-422.

Kerns, R., Rosenberg, R., \& Otis, J., (2002). Self-appraised problem solving and pain-relevant social support as predictors of the experience of chronic pain. Annals of Behavioral Medicine, 24, 100-105.

Kraaimaat, F., \& Evers, A. (2003). Pain-coping strategies in chronic pain patients: psychometric characteristics of the Pain-Coping Inventory (PCI). International Journal of Behavioral Medicine, 10, 343-363.

Lazarus, R., \& Folkman, S. (1984). Stress appraisal and copping. New York: Springer.
Lethem, J., Slade, P., Troup, J., \& Beutley, G. (1983). Outline of a fear-avoidance model of exaggerated pain perception - I. Behavioral Research Therapy, 21, 401-498.

López-Martínez, A., Esteve, R. y Ramírez-Maestre, C. (2008). Perceived social support and coping responses are independent variables explaining pain adjustment among chronic pain patients. The Journal of Pain, 9, 373-379.

McCracken, L., Vowles, K., \& Gauntlett-Gilbert, J. (2007). A prospective investigation of acceptance and control-oriented coping with chronic pain. Journal of Behavioral Medicine, 30, 339-349.

McCracken, L., Zavfert, C., \& Gross, R. (1992). The pain anxiety symptoms scale: development and validation of a scale to measure fear of pain. Pain, 50, 67-73.

McGuire, B., Hogan, M., Morrison, T. (2008). Dimensionality and reliability assessment of the Pain Patient Profile questionnaire. European Journal of Psychological Assessment, 24, 22-26.

Mellegard, M., Grossi, G., Soares, J. (2001). A comparative study of coping among women with fibromyalgia, neck/ shoulder and back pain. International Journal of Behavioural Medicine. 8, 103-115.

Melzack, R. (1979). The puzzle of pain. New York: Basic Books.

Melzack, R., \& Wall, P. (1965). Pain mechanisms: a new theory. Science, 150, 971-979.

Melzack, R., \& Wall, P. (1982). The challenge of pain. New York: Basic Books.

Meredith, P., Strong, J., \& Feeney, J. (2006). Adult attachment, anxiety, and pain self-efficacy as predictors of pain intensity and disability. Pain, 123, 146-154.

Merskey, H., Bogduk, N. (Eds) (1994). Classification of chronic pain: descriptions of chronic pain syndromes and definitions of pain terms (2nd ed.). Seattle: IASP Press.

Miró, J., Nieto, R., \& Huguet, A. (2008). Predictive factors of chronic pain and disability in whiplash: A Delphi poll. European Journal of Pain, 12, 30-47.

Morlion, B., Walch, H., Yihune, G., Vielvoye-Kerkmeer, A., de Jong, Z., Castro-Lopes, J., \& Stanton-Hicks, M. (2008). The Pain Associates' International Network Initiative: a novel practical approach to the challenge of chronic pain management in Europe. Pain Practice, 8, 473-480.

Mueller, A., Hartmann, M., Mueller, K., Eich, W. (2003). Validation of the arthritis self-efficacy short-form scale in German fibromyalgia patients. European Journal of Pain, 7, 163-171.

Munce, S., Stewart, D. (2007). Gender differences in depression and chronic pain conditions in a national epidemiologic survey. Psychosomatics, 48, 394-399.

Navalhas, J. (1998). Crise e suporte social, efeitos potenciais do suporte social. Revista de Psiquiatria do Hospital Júlio de Matos, 11, 27-46. 
Naughton, F. (1997). Stress and Coping. Retriev on May, 11, 2009, from http://www.csun.edu/ vcpsy00h/students/ coping.htm

Newth, S., \& Delongis, A. (2004). Individual differences, mood, and coping with chronic pain in rheumatoid arthritis: a daily process analysis. Psychology and Health, 19, 283-305.

Nicholas, M. (2007). The pain self-efficacy questionnaire: Taking pain into account. European Journal of Pain, 11, 153-163.

Novy, D. M., Nelson, D. V., Francis, D. J., \& Turk D.C. (2005). Perspectives of chronic pain: An evaluative comparison of restrictive and comprehensive models. Psycholgical Bulletin, 118, 238-247.

Páez-Blarrina, M., Luciano, C., Gutiérrez-Martínez, O., Valdivia, S., Rodríguez-Valverde, M., \& Ortega., J. (2008). Coping with pain in the motivational context of values: Control based protocol comparison between an acceptancebased and a cognitive. Behavior Modification, 32, 403-422.

Pain Associates' International Network. (2004). Consenso do Funchal: dor crónica múscolo-esquelética. Retrieved on June, 11, 2007, from http://www.grunenthal.com/cw/pt_ PT/pdf/cw_pt_pt_pain2.pdf;jsessionid=YDXWMI4WBF W1XLAQP2BCFEQ

Ramírez-Maestre, C., Esteve, R. \& López, A.E. (2008). Cognitive appraisal and coping in chronic pain patients. European Journal of Pain, 12, 749-756.

Ramírez-Maestre, C., López-Martínez, A., \& Esteve, R. (2004). Personality characteristics as differential variables of the pain experience. Journal of Behavioral Medicine, 27, 147-165.

Reuter, K., Classen, C., Roscoe, J., Morrow, G., Kirshner, J., Rosenbluth, R., et al. (2006). Association of coping style, pain, age and depression with fatigue in women with primary breast cancer. Psycho-Oncology, 15, 772-779.

Ribeiro, J., \& Santos, C. (2001). Estudo conservador de adaptação do Ways of Coping Questionnaire a uma amostra e contexto portugueses. Análise Psicológica, 4, 491-502.

Robinson, M., Dannecker, E., George, S., Otis, J., Atchinson, J., \& Fillingim, R. (2005). Sex differences in the associations among psychological factors and pain report: a novel psychophysical study of patients with chronic low back pain. The Journal of Pain, 6, 463-470.

Robb, K., Williams, J., Duvivier, V., \& Newham, D. (2006). Apain management program for chronic cancer-treatment-related pain: a preliminary study. The Journal of Pain, 7, 82-90.

Romano, J., Turner, J., \& Jensen, M. (1997). The family environment in chronic pain patients: comparison to controls and relationship to patient functioning. Journal of Clinical Psychology in Medical Settings, 4, 1573-3572.

Rosenstiel, A., \& Keefe, F. (1983). The use of coping strategies in chronic low back pain patients: relationship to patient characteristics and current adjustment. Pain, 17, 33-44.
Sanford, S., Kersh, B., Thorn, B., Rich, M., Ward, L. (2002). Psychosocial mediators of sex differences in pain responsivity. The Journal of Pain, 3, 58-64.

Santos, C., Ribeiro, J.L., \& Lopes, C. (2003). Estudo de adaptação da Escala de Satisfação com o Suporte Social (ESSS) a pessoas com diagnóstico de doença oncológica. Psicologia, Saúde \& Doenças, 4, 185-204.

Severeijns, R., Vlaeyen, J., van den Hout, M., \& Weber, W. (2001). Pain catastrophizing predicts pain intensity, disability, and psychological distress independent of the level of physical impairment. The Clinical Journal of Pain, 17, 165-72. [Abstract].

Soares, V. (1999). Avaliação da eficácia de um programa de intervenção psicológica multimodal em pacientes com dor crónica. Braga: Instituto de Educação e Psicologia da Universidade do Minho.

Strahl, C., Kleinknecht, R., \& Dinnel, D. (2000). The role of pain anxiety, coping, and pain self-efficacy in rheumatoid arthritis patient functioning. Behaviour Research and Therapy, 38, 863-873.

Sullivan, M., Bishop, S., \& Pivik, J. (1995). The pain catastrophizing scale: development and validation. Psychological Assessement, 7, 524-532.

Tamres, L., Janicki, D., Helgeson, V. (2002). Sex differences in coping behavior: a meta-analytic review and an examination of relative coping. Personality and Social Psychology Review, 6, 2-30.

Tan, G., Jensen, M., Thornby, J., Rintala, D., \& Anderson, K. (2008). Categorizing pain in patients seen in a veterans health administration hospital: Pain as the fifth vital sign. Psychological Services, 5, 239-250.

Tsai P., Tak S., Moore, C. \& Palencia, I. (2003). Testing a theory of chronic pain. Journal of Advanced Nursing, 43, 158-169.

Tsang, A., Von Korff, M., Lee, S., Alonso, J., Karam, E., Angermeyer, M., et al. (2008). Common chronic pain conditions in developed and developing countries: gender and age differences and comorbidity with depression-anxiety disorders. The Journal of Pain, 9, 883-891.

Tunks, E., Weir, R., \& Crook, J. (2008). Epidemiologic perspective on chronic pain treatment. The Canadian Journal of Psychiatry, 53, 235-241.

Turk, D., \& Okifuji, A. (2002). Psychological factors in chronic pain: evolution and revolution. Journal of Consulting and Clinical Psychology, 70, 678-690.

Turner, J., Ersek, M., \& Kemp, C. (2005). Self-efficacy for managing pain is associated with disability, depression, and pain coping among retirement community residents with chronic pain. The Journal of Pain, 6, 471-479.

Turner, J., Jensen, M., Warms, C., \& Cardenas, D. (2002). Catastrophizing is associated with pain intensity, psychological distress, and pain-related disability among individuals with chronic pain after spinal cord injury. Pain, 98, 127-134. 
Unruh, A. (1996). Gender variations in clinical pain experience. Pain, 65, 123-167.

Valente, M., Pais-Ribeiro, J., \& Jensen, M. (2009). Dor crónica músculo-esquelética: influência do coping, ansiedade e depressão. Poster session presented at the $7 .^{\circ}$ Convénio da Astor, 16.as Jornadas da Unidade de Dor do Hospital Garcia de Orta, Lisbon, Portugal.

Van Damme, S., Crombez, G., Eccleston, C. (2008). Coping with pain: a motivational perspective. Pain, 139, 1-4.

Vlaeyen, J., Kole-Snijders, A., Boeren, R., \& vanEek, H., (1995). Fear of movement/(re) injury in chronic low back pain and its relation to behavioral performance. Pain, 62, 363-372.

Vlaeyen, J., \& Linton, S. (2000). Fear-avoidance and its consequences in chronic musculoskeletal pain: a state of the art. Pain, 85, 317-332.

Wachholtz, A., Pearce, M., \& Koenig, H. (2007). Exploring the relationship between spirituality, coping, and pain. Journal of Behavioral Medicine, 30, 311-318.

Waddell, G., Newton, M., Henderson, J., Somerville, D., \& Main, C. (1993). A fear-avoidance beliefs questionnaire (FABQ) and the role of fear-avoidance beliefs in chronic low back pain and disability. Pain, 52, 157-168.
Woby, S., Roach, N., Urmston, M., \& Watson, P. (2007). The relation between cognitive factors and levels of pain and disability in chronic low back pain patients presenting for physiotherapy. European Journal of Pain, 11, 869-877.

Wolff, B., Burns, J., Quartana, P., Lofland, K., Bruehl, S., \& Chung, O. (2008). Pain catastrophizing, physiological indexes, and chronic pain severity: tests of mediation and moderation models. Journal of Behavioral Medicine, 31, 105-114.

Zaza, C., \& Baine, N. (2002). Cancer pain and psychological factors: a critical review of the literature. Journal of Pain and Symptom Management, 24, 526-542.

Zaza, C., Reynob, L., \& Moulin, D. (2000). The Multidimensional Pain Inventory profiles in patients with chronic cancer-related pain: an examination of generalizability. Pain, $87,75-82$.

Received March 19, 2009

Accepted June 17, 2009 